\title{
Internal consistency and factor structure of the adherence scale for alcoholics anonymous
}

\section{Consistência interna e estrutura fatorial da escala de adesão aos alcoólicos anônimos}

\author{
Mauro Barbosa TERRA \\ Helena Maria Tannhauser BARROS \\ Airton Tetelbom STEIN² \\ Ivan FIGUEIRA ${ }^{3}$ \\ Luciana Dias ATHAYDE \\ Dartiu Xavier da SILVEIRA ${ }^{4}$
}

\begin{abstract}
The objective of the article was to estimate the internal consistency and factor structure of the Adherence Scale for Alcoholics Anonymous Groups. The scale was applied to 257 alcoholic patients who had been admitted for treatment in 3 hospitals in Porto Alegre, about 6 months earlier. The scale was produced based on an adaptation of the Drug Attitude Inventory Scale. Internal consistency was measured using Cronbach alpha. Data were subjected to a principal component analysis. The coefficient of internal consistency was 0.71. All items showed corrected item-total correlation coefficients above 0.29. Questionnaire items with factor loading of 0.57 or above were considered in the final factor solution. The factor analysis resulted in 2 dimensions which corresponded to $67.01 \%$ of the total variance. This scale appears to be a valid instrument for use in a population of alcoholic patients.
\end{abstract}

Uniterms: Alcoholism. Alcoholics anonymous. Internal consistency. Factor analysis.

\section{Resumo}

O objetivo do artigo foi estimar a consistência interna e a estrutura fatorial da Escala de Adesão a Grupos de Alcoólicos Anônimos. A escala foi aplicada em 257 pacientes dependentes de álcool, que estavam em tratamento em 3 hospitais em Porto Alegre, 6 meses antes. A escala foi elaborada a partir de uma adaptação da Drug Attitude Inventory Scale. A consistência interna da escala foi medida pelo Alfa de Cronbach. Os dados foram submetidos à análise do componente principal. O coeficiente de consistência interna foi 0,71. Todos os itens mostraram coeficientes de correlação entre o item e a totalidade dos itens maiores do que 0,29. Os itens da escala com carga fatorial igual ou maior do que 0,57 foram considerados na solução fatorial final. A análise fatorial resultou em 2 dimensões, as quais corresponderam a 67,01\% da variância total. Essa escala parece ser um instrumento válido para uso em alcoolistas.

Unitermos: Alcoolismo. Alcoólicos anônimos. Consistência interna. Análise fatorial.

\section{$\nabla \nabla \nabla \nabla$}

1 Universidade Federal de Ciências da Saúde de Porto Alegre, Divisão de Farmacologia Básica e Clínica. R. Sarmento Leite, 245, Sala 325, 30 andar, Centro, 90050-170, Porto Alegre, RS, Brasil. Correspondence to/Correspondência para: M.B. TERRA. E-mail: <mabarte@portoweb.com.br>.

2 Universidade Federal de Ciências da Saúde de Porto Alegre, Departamento de Medicina Preventiva. Porto Alegre, RS, Brasil.

3 Universidade Federal do Rio de Janeiro, Departamento de Psiquiatria. Rio de Janeiro, RJ, Brasil.

4 Universidade Federal de São Paulo, Programa de Orientação e Atendimento a Dependentes. São Paulo, SP, Brasil.

Sponsors: The study was partially supported by the Brazilian research funding agencies (Fundação de Amparo à Pesquisa do Estado do Rio Grande do Sul - process n॰ 04/08100-5 and Fundação de Amparo à Pesquisa do Estado de São Paulo - process n 02/0071.1). 
Alcoholism can be treated in several ways, one of them via a combined medical and psychotherapeutic approach. Among the possible alternatives, alcoholics anonymous provides an informal treatment adjunct to professional care, using a support community of volunteers who do not use alcohol. The positive effect of self-help groups reflects several factors, such as learning new coping strategies and changing one's social network to interact with abstinent individuals (Kaskutas, Bond \& Humphreys, 2002).

Patients can refer to alcoholics anonymous groups as part of a multiple treatment approach. Members publicly acknowledge their alcoholism and abstinence is the basic rule. Members join a group of peers who are currently abstinent, learning that it is possible to participate in social gatherings without drinking; the achievements of the abstinent members of the group are used as a model for recovery (Schuckit, 1999). This is of great importance since the alcoholic tends to find it difficult to reconstruct his own identity through social interaction and, in many cases, is influenced by his own social group to return to addictive behavior, albeit involuntarily (Campos \& Ferreira, 2007).

The alcoholics anonymous group follows the model of chemical dependence as a chronic disease, being congruous with metaphors used by alcoholics such as: a self-help group is a "sanctuary" for the restoration of dignity and human freedom, rescuing the alcoholic from the "bottom" or "gutter", or the alcoholics anonymous group is seen as a "lifeline", allowing one to return to life after believing oneself resigned to death from drug use (Baus, Seara, Caldas, Desidério \& Petry Filho, 2002)

Despite its popularity, alcoholics anonymous remains a less well understood and less frequently assessed approach to treatment for alcoholism (Morgenstern, Labouvie, McCrady, Kahler \& Frey, 1997). Nevertheless, alcoholics anonymous claims a sobriety rate of $75 \%$ to $81 \%$ for alcoholics heavily loyal to the program (Vederhus \& Kristensen, 2006). The main issue in the effectiveness of the model concerns adherence. Prolonged abstinence has been reported among adherent members (Gossop et al., 2003), and lower relapse rates have been associated with stronger engagement (Morgenstern et al., 1997) or more frequent attendance at meetings (Gossop et al., 2003; R. Moos, Schaefer, Andrassy \& B. Moos, 2001). However, no more than $35 \%$ of the patients referred to alcoholics anonymous attend the meetings consistently (Terra et al., 2006); around 50\% of the participants abandon treatment within the first 3 months (Fiorentine, 1999), and 60\% leave within 6 months (Gossop et al., 2003).

The mere presence at meetings may be a poor indicator of commitment among those encouraged to attend meetings. Perhaps the unavailability of other aspects of alcoholics anonymous may be responsible for the high percentage of abandonment or sporadic attendance of the program. People who value their feelings and are able to share them with the others usually show more engagement in alcoholics anonymous (Caldwell \& Cutter, 1998). An assessment of specific aspects of membership is important to understand the reasons for adherence to alcoholics anonymous. The influence of comorbid conditions and demographic characteristics on adherence to these groups has already been documented (Terra et al., 2007).

Alcoholics anonymous is believed to be an effective intervention for alcoholism, but relatively few studies on the benefits and on adherence to the method have been carried out (Jordan, Davidson, Herman \& BootMiller, 2002; Kownacki \& Shadish, 1999). As most research has been conducted in the United States, findings cannot be extrapolated to other contexts due to cultural differences.

The main purpose of this qualitative study was to estimate internal consistency and factor structure of a scale created to assess Brazilian alcoholic patients' adherence to alcoholics anonymous. This scale was modeled after the Drug Attitude Inventory (Hogan, Awad \&Easwood, 1983), the number and type of items selected being those chosen after a context validation assessment made by a group of experts involved in adapting and building instruments.

\section{Method}

\section{Participants}

Initially, 300 alcoholic patients were interviewed. They were hospitalized at two psychiatric hospitals and at a center specialized in chemical dependence in a 
general hospital in Porto Alegre. The patients'ages ranged between 20 and 60 years, and they met the inclusion criteria of a diagnosis of alcohol dependence according to responses to the Structured Clinical Interview for DSMIV-Axis I Disorders - Patient Edition (SCID-I/P) (First, Spitzer, Gibson \& Williams, 1996), and had been referred to alcoholics anonymous by their doctor. They all lived in Porto Alegre and had a telephone number where they could be reached. All patients were recruited between December 2001 and July 2003.

Exclusion criteria were: presence of a diagnosis of schizophrenia, acute psychotic disorder, mental retardation, confusional states, severe antisocial personality disorder, or presence of either decompensated cirrhosis or some other debilitating, physical condition. Exclusions were made on the basis of information collected from medical records and through psychiatric evaluation. About $10 \%$ of all patients contacted were excluded during the interview for mental retardation (2\%), confusional states (5\%) or severe antisocial personality disorder (3\%).

This research is part of a longitudinal study characterizing a cohort. During the first phase, when all 300 patients were still hospitalized, they were invited to participate in the study. The objectives and the interview procedures were explained. All patients signed a free and informed consent form before being included in the sample, and the project was approved by the Research Ethical Committee of the Universidade Federal de São Paulo, protocol number 0589/04, May 28, 2004, as well as the treatment institutions in which the study was conducted. The patients, after an abstinence period of at least one week, were interviewed by psychiatrists specially trained for this study.

The second phase of the study occurred 6 months after the first interview, when the patients were interviewed again in their homes. In this phase, the research was performed with a total of 257 alcoholic patients: 235 (91.4\%) men and 22 (8.6\%) women. Their Mean (M) age was 41.5years (Standard Deviation-SD = 8.6). These patients were interviewed by students with specialization in psychiatrics and by undergraduates of medicine, who were trained for the application of instruments, but were not aware of the objective of the study in order to control bias. Telephone contact was made to schedule the interviews, which were performed at the patients' homes, preferably in the absence of their relatives.

\section{Measures}

The SCID-I/P, a semi-structured clinical interview based on DSM-IV, was used by psychiatrists to check the diagnosis of alcohol dependence and other drugs in all patients, at the time they were hospitalized.

Since measures of alcoholics anonymous affiliation such as, the Recovery Interview (Morgenstern, Kahler, Frey \& Labouvie, 1996), the alcoholics anonymous Involvement Scale (Tonigan, Connors \& Miller, 1996), and the alcoholics anonymous Affiliation Scale (Humphreys, Kaskutas \&Weisner, 1998) have not been translated into Portuguese or been validated for use in Brazil, a new scale to assess adherence to alcoholics anonymous was constructed by adapting items in the Drug Attitude Inventory (Hogan et al., 1983). This scale was designed for use in assessing adherence by schizophrenic patients to a drug treatment. It is a dichotomous scale in which the patient responds "yes" or "no" and with an easy-toapply indicator of regularity with which the patient takes pills during therapy. Factors which influence adherence are covered and the Drug Attitude Inventory has been translated into Portuguese (Rosa \& Marcolin, 2000). The adapted version was found to be interesting from both the clinical experience and from adherence by schizophrenics who abused alcohol, but no data has been published. Furthermore, psychometric properties of this adapted scale remain to be evaluated. The scale was administered in the second phase of the main study, 6 months after the first interview.

A questionnaire to document the relationship of patients in alcoholics anonymous was also administered (attendance records, behavior in the groups). Adherence was considered to be strong if alcoholics anonymous attendance occurred at least twice a week; partial if attendance was once a week or once every other week; weak if attendance was once a month or sporadic; and no adherence when there was no attendance.

Periodic evaluations were performed in respect of the interviews. The Kappa test, employed in assessing 
compliance with the SCID-I administration, was 0.86 (Gordis, 1996).

Internal consistency was estimated as the Cronbach alpha (Cronbach, 1951). The corrected itemtotal correlations were calculated for each item of the scale. Items whose correlations were less than 0.15 were considered to have poor correlation with others (Everitt, 1983). Data were subjected to a principal component analysis, since this method does not require normal data distribution. Questionnaire items with a loading of 0.57 or above were considered in the final factor solution (Child, 1990). Principal component analysis was applied to identify possible dimensions. A matrix derived through varimax rotation was obtained to meet Thurstone's requirements. According to Thurstone, solutions should be invariant, unique and in accordance with non-factorial research findings. The number of components to be retained was based on a scree plot, whose curve suggests that 2 dimensions could encompass data variability. The scale's final score was the sum of all items. Statistical analysis was based on the Statistical Package for the Social Sciences software (SPSS Incorporation, 1997).

\section{Results}

The diagnosis of alcohol dependence was corroborated by analysis of responses to SCID-I/P by all patients. At the 6-month follow-up, 19.1\% $(n=49)$ of the alcoholics adhered to alcoholics anonymous, and 58.3\% of these showed strong adherence, 35.4\% showed partial adherence, and 5.3\% weak adherence to the alcoholics anonymous .
Regarding the types of drugs used, $70.4 \%$ used only alcohol and $29.6 \%$ used other drugs besides alcohol, with 13\% using alcohol plus cocaine, $7.3 \%$ alcohol plus cocaine plus marijuana, $6 \%$ alcohol plus marijuana, 1\% alcohol plus benzodiazepines and 2.3\% alcohol plus other drugs.

\section{Reliability/Internal consistency}

The scale's coefficient of internal consistency was 0.71. No item showed corrected item-total correlations lower than 0.29 (Table 1).

\section{Factor analysis}

The principal component analysis applied to completed questionnaires extracted two factors, accounting for $67.0 \%$ of the total data variance. Item loadings for the two rotated factors are in Table 2. Factor I was composed of items 1 to 8, corresponding to the dimension "perceived benefits". This factor encompasses $56.6 \%$ of the explained variance. Item 9 encompasses $10.3 \%$ of the explained variance. The measure of internal consistency assessed using Cronbach alpha was 0.87 for the first factor. Eigenvalues for each factor are displayed in Table 2. Two poorly correlated items were not excluded from the final analysis, because the aim was to report the psychometric properties of the entire, adapted version of the original scale. Obviously, in a subsequent step, deletion of items 1 and 7 may result in an even better scale.

Comparison of the mean scores of the 9-item Adherence Scale for alcoholics anonymous Groups by

Table 1. Corrected item-total correlations for items of the adherence scale for alcoholics anonymous groups ( $n=251)$. Porto Alegre (RS), 2004.

\begin{tabular}{|c|c|c|c|}
\hline & Item & Content & Corrected item total items correlation \\
\hline \multirow{7}{*}{ 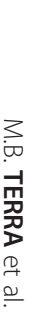 } & 1 & For me alcoholics anonymous offers more good things than bad things & 0.41 \\
\hline & 2 & I'm more aware of what I'm doing and what's going on around me when I go to alcoholics anonymous & 0.72 \\
\hline & 3 & Attending alcoholics anonymous makes me feel more relaxed & 0.71 \\
\hline & 4 & I relate with people better when I go to alcoholics anonymous & 0.73 \\
\hline & 5 & I feel normal when I go to alcoholics anonymous & 0.70 \\
\hline & 6 & I feel happier and better when I go to alcoholics anonymous & 0.77 \\
\hline & 7 & I attend alcoholics anonymous to change behaviors other people don't like & 0.29 \\
\hline 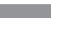 & 8 & I have better control over myself when I go to alcoholics anonymous & 0.81 \\
\hline & 9 & Attending to alcoholics anonymous prevents me from drinking & 0.76 \\
\hline
\end{tabular}


Table 2. Two-factor structure of the adherence scale for alcoholics anonymous groups. Porto Alegre (RS), 2004.

\begin{tabular}{|c|c|c|}
\hline Item & Content & Loading \\
\hline \multicolumn{3}{|c|}{ Factor I (Perceived benefit), Eigenvalue $=5.09$, Explained variance $=56.64 \%$, alpha $=0.87$} \\
\hline 6 & I feel happier and better when I go to alcoholics anonymous & 0.85 \\
\hline 8 & I have better control over myself when I go to alcoholics anonymous & 0.84 \\
\hline 9 & Attending alcoholics anonymous prevents me from drinking & 0.81 \\
\hline 2 & I'm more aware of what I'm doing and what's going on around me when I go to alcoholics anonymous & 0.79 \\
\hline 3 & Attending alcoholics anonymous makes me feel more relaxed & 0.79 \\
\hline 4 & I relate with people better when I go to alcoholics anonymous & 0.78 \\
\hline 5 & I feel normal when I go to alcoholics anonymous & 0.73 \\
\hline 1 & For me alcoholics anonymous offers more good things than bad things & 0.57 \\
\hline \multicolumn{3}{|c|}{ Factor II, Eigenvalue $=0.93$ Explained variance $=10.37 \%$} \\
\hline 7 & I attend alcoholics anonymous to change behaviors other people don't like & 0.92 \\
\hline
\end{tabular}

Table 3. Mean scores on the adherence scale for alcoholics anonymous groups (9-item version) of alcohol-dependent patients under treatment. Porto Alegre (RS), 2004.

\begin{tabular}{|c|c|c|c|c|c|}
\hline & & $n$ & Mean & Standard deviation & $p$ \\
\hline \multirow[t]{2}{*}{ Sex } & Men & 119 & 5.53 & 3.30 & \multirow{2}{*}{ n.s. } \\
\hline & Women & 16 & 4.87 & 3.40 & \\
\hline \multirow[t]{4}{*}{ Age group } & $20-30$ & 9 & 4.11 & 3.00 & \multirow{4}{*}{ n.s. } \\
\hline & $31-40$ & 41 & 5.27 & 3.30 & \\
\hline & $41-50$ & 62 & 5.89 & 3.20 & \\
\hline & $51-59$ & 23 & 5.13 & 3.50 & \\
\hline \multirow[t]{2}{*}{ Adherence } & Adhering & 28 & 7.46 & 2.40 & \multirow{2}{*}{$p<0.001$} \\
\hline & Non-adhering & 107 & 4.92 & 3.30 & \\
\hline
\end{tabular}

sex, age and adherence to alcoholics anonymous groups are shown in Table 3. The mean scores for adhering and non-adhering patients were $7.5(\mathrm{SD}=2.4)$ and 4.9 $(S D=3.3)$ respectively for the 9-item scale $(t=4.61$; $p<0.001)$. When using the reduced 7-item scale, the mean scores were $5.8(\mathrm{SD}=1.8)$ for adhering patients and $3.9(\mathrm{SD}=2.5)$ for drop-outs, respectively $(\mathrm{t}=4.59 ; p<0.001)$, suggesting that both versions seem to be predictive of adherence.

\section{Discussion}

This study was the first to evaluate the psychometric properties of a scale aiming to assess adherence to alcoholics anonymous in Brazil. Procedures were used to evaluate the internal consistency and the factor structure of the instrument.

The Cronbach alpha method was applied to evaluate the scale's homogeneity. Lack of reliability has been a particular concern for researchers using selfreported information. To improve assessment reliability, researchers have produced measures using itemsymptoms, to evaluate different aspects of a given condition (Da Silveira \& Jorge, 1997). Scores of symptom scales were seen to present better reliability than separate items, improvement in reliability being a direct function of the number of items in the scale, as long as these items are positively correlated (Shrout \& Yager, 1989). It is important to evaluate the reliability of measures since, according to psychometric principles, if a measure is not reliable, it cannot be considered as valid. If the items of a given scale measure the same construct, the internal consistency of the scale may be considered as a reliability index (Lord \& Novick, 1968). The internal consistency of the scale was 0.71 , a value at the lower margin of acceptability. Factor analysis defined 2 factors which encompassed $67.02 \%$ of the total data variability. Since two items were apparently not 
measuring exactly the same construct, the use of a reduced 7-item scale should be considered.

Adherence to alcoholics anonymous was low in this patient sample. Findings agree with another follow-up investigation conducted 6 months after hospitalization, which showed that this treatment strategy was limited to a small numbers of patients, since the adherence rate was only 40\%, though larger than that observed in the present study (Gossop et al., 2003).

The study presents a number of limitations. The sample consisted of alcoholic patients who had been hospitalized in 3 hospitals in the city of Porto Alegre, Brazil, not necessarily being representative of the overall alcoholic population. Skewness of the sample might also have influenced the outcomes. Further research is needed to evaluate the performance of the scale in the community and in other clinical populations to check if it maintains similar or better psychometric properties in distinct settings.

The scale proved to be a reliable and structurally valid instrument for use in a population of alcoholic patients. The possibility of screening for adherence to alcoholics anonymous, using a brief scale like this one, is plausible. The scale has potential applications in both clinical and research settings. Program managers can use this information to assess the extent to which their patients are effectively involved in alcoholics anonymous as well as to compare adherence of patients to other programs, which may, accordingly, provide an indication of how to modify their interventions.

\section{References}

Baus, J., Seara, A. C., Caldas, C. M., Desidério, L., \& Petry Filho, W. (2002). Metáforas e dependência química. Estudos de Psicologia (Campinas), 19 (3), 5-13. doi: 10.1590/S0103-1 66×2002000300001.

Caldwell, P. E., \& Cutter, H. S. G. (1998). Alcoholics anonymous affiliation during early recovery. Journal of Substance Abuse Treatment, 15 (3), 221-228.

Child, D. (1990). The essentials of factor analysis ( $2^{\text {nd }}$ ed.). London: Biddles.

Campos, G. M., \& Ferreira, R. F. (2007). A importância da legitimação social na (re)construção da identidade de um alcoolista. Estudos de Psicologia (Campinas), 24 (2),
Cronbach, L. J. (1951). Coefficient alpha and the internal structure of tests. Psychometrika, 16 (3), 297-333.

Da Silveira, D. X., \& Jorge, M. R. (2002). Reliability and factor structure of the Brazilian version of the center for epidemiologic studies-depression. Psychology Reports, 91 (1), 865-874.

Everitt, B. S., \& Dunn, G. (1983). Advanced methods of data exploration and modelling. London: Heinemann Educational Books.

Fiorentine, R. (1999). After drug treatment are 12-step programs effective in maintaining abstinence? The American Journal of Drug and Alcohol Abuse, 25 (1), 93-116.

First, M. B., Spitzer, R. L., Gibson, M., \& Williams, J.B. (1996). Structured Clinical interview for DSM-IV Axis I Disorders: patient edition (SCID I/P, Version 2.0). Washington, DC: American Psychiatric Association.

Gordis, L. (1996). Epidemiology. Philadelphia, PA: WB Saunders.

Gossop, M., Harris, J., Best, B., Lan-Ho, M., Manning, V., Marshall, J., et al. (2003). Is attendance at alcoholics anonymous meetings after inpatient treatment related to improved outcomes? A 6-month follow-up study. Alcohol \& Alcoholism, 38 (5), 421-426.

Hogan, T. P., Awad, A. G., \& Eastwood, R. (1983). A selfreport scale predictive of drug compliance in schizophrenics: reliability and discriminative validity. Psychological Medicine, 13 (1), 177-183.

Humphreys, K., Kaskutas, L. A., \& Weisner, C. (1998). The Alcoholics Anonymous Affiliation Scale: development, reliability, and norms for diverse treated and untreated populations. Alcohololism: Clinical and Experimental Research, 22 (5), 974-978.

Jordan, L. C., Davidson, W. S., Herman, S. E., \& BootMiller, B. J. (2002). Involvement in 12-step programs among persons with dual diagnoses. Psychiatric Services, 53 (7), 894-896.

Kaskutas, L. A., Bond, J., \& Humphreys, K. (2002). Social networks as mediators of the effect of Alcoholics Anonymous. Addiction, 97 (9), 891-900.

Kownacki, R. J., \& Shadish, W. R. (1999). Does alcoholics anonymous work? The results from a meta-analysis of controlled experiments. Substance Use \& Misuse, 34 (13), 1897-1916.

Lord, F. M., \& Novick, M. R. (1968). Statistical theories of mental test scores. Reading, MA: Addison-Wesley.

Moos, R., Schaefer, J., Andrassy, J., \& Moos, B. (2001). Outpatient mental health care, self-help groups, and patients one-year treatment outcomes. Journal of Clinical Psychology, 57 (3), 273-287.

Morgenstern, J., Kahler, C. W., Frey, R. M., \& Labouvie, E. (1996). Modeling therapeutic response to 12-step treatment: optimal responders, non-responders, and partial responders. Journal of Substance Abuse, 8 (1), 45-59.

Morgenstern, J., Labouvie, E., McCrady, B. S., Kahler, C. W., \& Frey, R. M. (1997). Affiliation with alcoholics anonymous 
after treatment: a study of its therapeutic effects and mechanisms of action. Journal of Consulting and Clinical Psychology, 65 (5), 768-777.

Rosa, M. A., \&Marcolin, M. A. (2000). Translation and adaptation of the Rating of Medication Influences (ROMI): an instrument to assess compliance to treatment. Jornal Brasileiro de Psiquiatria, 49 (10), 405-412.

Schuckit, M. A. (1999). Alcohol disorders. In H. I. Kaplan \& B. J. Sadock (Org.), Textbook of psychiatry (6th ed., pp.838855). Porto Alegre: Artmed.

Shrout, P. E., \& Yager, T. J. (1989). Reliability and validity of screening scales: effect of reducing scale length. Journal of Clinical Epidemiology, 42 (1), 69-78.

SPSS Incorporation. (1997). Statistical package for social sciences - SPSS. Chicago, IL: Release 8.0. SPSS Inc.

Terra, M. B., Barros, H. M. T., Stein, A., Figueira, I., Athayde, L. D., Palermo, L. H., et al. (2007). Predictors of engagement in the Alcoholics Anonymous group or to psychotherapy among Brazilian alcoholics: a six-month follow-up study. European Archives of Psychiatry and Clinical Neuroscience, 257 (4), 237-244.

Terra, M. B., Barros, H.M. T., Stein, A., Figueira, I., Athayde, L. D., Spanemberg, L., et al. (2006). Does co-occurring social phobia interfere with alcoholism treatment adherence and relapse? Journal of Substance Abuse Treatment, 31 (4), 403-409.

Tonigan, J. S., Connors, G. J., \& Miller, W. R. (1996). Alcoholics Anonymous Involvement Scale: reliability and norms. Psychology of Addictive Behaviors, 10 (2), 75-80.

Vederhus, J. K., Kristensen, O. (2006). High effectiveness of self-help programs after drug addiction therapy. BMC Psychiatry, 23 (6), 35.

Received on: 24/6/2009

Final version resubmitted on: 25/11/2010

Approved on: 1/12/2010 